\title{
TÜNDE SZABÓ
}

Pécsi Tudományegyetem, BTK, Szláv Filológiai Tanszék

7624 Pécs

Ifjúság útja 6

sztunde1512@gmail.com

\section{БИОГРАФИЯ И ОРНАМЕНТАЛИЗМ В ПОСТ- МОДЕРНИСТСКОМ РОМАНЕ О ДОСТОЕВСКОМ (ЛЕТО В БАДЕНЕ Л. ЦЫПКИНА)}

\section{BIOGRAPHY AND ORNAMENTALISM - A POSTMODERN NOVEL ABOUT DOSTOYEVSKY (LEONID TSYPKIN'S SUMMER IN BADEN-BADEN)}

\begin{abstract}
В статье рассматривается роман Л. Цыпкина Лето в Бадене одновременно и как современная версия орнаментальной прозы русских символистов и как постмодернистский миф о Достоевском-игроке. В сюжете романа, основанном на первоисточниках, прежде всего на дневнике А. Г. Достоевской, выделяется чувство униженности как основное слагаемое нравственно-психологического облика Достоевского-героя. С точки зрения орнаментализма, благодаря приему повтора разнообразных эквивалентных элементов, в романе изображается преодоление чувства униженности, которое в тексте реализуется с помощью метафор «стремления вверх». В результате в романе происходит перекодировка мотивной структуры романа Игрок, наиболее автобиографического романа Ф. М. Достоевского.
\end{abstract}

Ключевые слова: Л. Цыпкин, Ф. М. Достоевский, постмодернистский миф, орнаментальная проза.

The paper examines how Leonid Tsypkin's novel Summer in Baden-Baden utilises the apparatus of symbolist ornamental prose, one of the characteristic features of Russian Modernism, while it applies postmodern devices to construct the myth of Dostoyevsky as a gambler. The plot of Tsypkin's novel, which relies on primary sources, especially Anna Dostoyevskaya's diary, highlights the feeling of humiliation as a central component of the personality of Dostoyevsky as a character. At the same time, on the ornamental level of the text, repetitive motifs and equivalences are applied with the aim of placing emphasis on transcending the humiliation, which can be achieved through "aspiring for the summit" and a network of motifs connected with it. As a result, the motif structure of The Gambler, the most autobiographical of Dostoyevsky's novels, becomes transcoded.

Keywords: Leonid Tsypkin, Fyodor Dostoyevsky, postmodern myth, ornamental prose. 
Постмодернистские произведения часто вовлекают в игру не только фрагменты текстов, принадлежащих самым разным культурам, литературным эпохам и авторам, но и образы самих же авторов. С помощью игрового воспроизведения образа писателя-предшественника они деконструируют, перекодируют, а порой развивают сложившийся миф об авторе, определяя при этом свою позицию по отношению к автору и его творчеству. Одним из таких произведений, как нам представляется, является Лето в Бадене Л. Цыпкина (1926-1982), главным героем которого выступает Ф. М. Достоевский.

История романа Цыпкина не совсем обычна. Автору, врачу-патологоанатому по профессии, писавшему исключительно в стол, никогда не довелось увидеть свое произведение напечатанным. Рукопись была тайком вывезена из СССР, а Цыпкин скончался в Москве, неделю спустя после публикации первого отрывка произведения в американском журнале «Новая Газета» в марте 1982 года. Роман вскоре был переведен - сначала на немецкий, а потом на английский языки, но так и оставался незамеченным, пока его не обнаружила Сюзан Зонтаг на «одном из книжных развалов лондонской Черинг Кросс Роуд» ${ }^{1}$. С. Зонтаг оценила найденный ею роман очень высоко:

Этот роман я, ничуть не усомнившись, включила бы в число самых выдающихся, возвышенных и оригинальных достижений века, полного литературы и литературности - в самом широком смысле этого определения ${ }^{2}$

- писала она в предисловии к переизданию романа в 2001 году. Благодаря высокой оценке С. Зонтаг и ее огромному желанию познакомить с произведением Цыпкина широкую публику, роман стал сенсацией на Западе и получил очень хорошие отзывы. В России Лето в Бадене впервые вышло отдельным изданием в 2003 году и вызвало противоположную реакцию со стороны критики. Одни, как и С. Зонтаг, считали его шедевром, романом «о любви к Достоевскому»³. Другие, наоборот, воспринимали его как незаслуживающее внимания произведение, представляющееся «не слишком интересным предметом для разговора» 4 .

${ }^{1}$ С. Зонтаг, Любить Достоевского, [в:] Л. Цыпкин, Лето в Бадене, Москва: Новое литературное обозрение 2003, с. 5.

2 Там же.

${ }^{3}$ Ю. Чупринина, 170 странии про любовь, «Итоги» 2003, № 19, с. 361, [электронный ресурс] http://www.itogi.ru/archive/2003/19/82612.html [10.08.2017]. «Апофеозом литературы» называет роман Цыпкина М. Туровская в своей работе Лето в Бадене, или большое приключение литературы, «Зарубежные записки» 2005, № 2, [электронный pecypc] http://magazines.russ.ru/zz/2005/2/tu13.html [21.08.2017]. «Лето в Бадене - это [...] постоянное изучение себя в Достоевском и Достоевского в себе» - оценивает роман А. Левинтон в работе Роман длиною в несколько абзащев, [электронный ресурс] http:// berkovich-zametki.com>Nomer37/Levintov1.htm [10.08.2017].

${ }^{4}$ М. Эдельштейн, Леонид Цыпкин. Лето в Бадене, «Знамя» 2004, № 6. М. Лемхин видит в романе всего лишь «нехитрую схему любви-ненависти к несправедливому отцу и соперничества за его наследство». М. Лемхин, Доктор Цыпкин и доктор Гинденбург, «Новый мир» 2004, № 6, [электронный ресурс] http://magazines.russ.ru/novyi_mi/2004/7/ lem11-pr.html [21.08.2017]. 
Придерживаясь нейтральной позиции в этой полемике, в настоящей работе мы лишь хотим показать, как опыт модернизма используется в сугубо постмодернистском тексте при создании художественного образа писателя XIX века.

Подобный угол зрения на произведение Цыпкина может оказаться интересным и потому, что, в связи с отношением постмодернизма к модернизму, мнения литературоведов тоже расходятся. М. Эпштейн, например, в своей известной работе Постмодернизм и коммунизм выделяет именно антимодернизм как одну из схожих черт эстетики двух эпох: «Постмодернизм и коммунизм обнаруживают сходство в своем неприятии модернизма (и всех его школ) как устаревшего, „камерного” направления в искусстве ${ }^{5}$. Н. Н. Кякшто, наоборот, отличительную черту русского постмодернизма видит в том, что «в нем отчетливо звучит память о модернизме Серебряного века ${ }^{6}$. Поэтика романа Лето в Бадене подтверждает мнение Н. Кякшто, поскольку произведение Цыпкина, на наш взгляд, является постмодернистской версией орнаментальной прозы, разработанной русскими символистами в начале XX века.

\section{Биография}

Название романа указывает на один из переломных периодов жизни Ф. М. Достоевского, а именно 1867 год. Шестидесятые годы - время бурных событий и переживаний в жизни писателя. Это и страстная любовная связь с А. Сусловой, это и поездки за границу и увлечение азартными играми, это и смерть первой жены и любимого брата Михаила, это и грозящие тюрьмой долги и кабальный договор с издателем Ф. Т. Стелловским. Совместная работа с молодой стенографисткой А. Г. Сниткиной над романом Игрок, сюжет которого теснейшим образом связан с перечисленными событиями ${ }^{7}$ привела ко второму браку и новым перспективам в жизни писателя.

Во время их совместной поездки в Германию Достоевский все еще продолжал увлекаться рулеткой, и поэтому в центре первых двух частей романа Цыпкина стоят именно метания писателя между молодой женой

${ }^{5}$ М. Эпштейн, Постмодернизм и коммунизм, [в:] он же, Постмодерн в русской литературе, Москва: Высшая школа 2005, с. 75.

${ }^{6}$ Н. Н. Кякшто, Русский постмодернизм, [в:] Русская литература ХХ века. Школь, направления, методы творческой работы, науч. ред. С. И. Тимина, Москва: Logos 2002, c. 309.

7 Л. Сараскина подчеркивает необычную, предельную биографичность романа: «Игрок - это сочинение, в котором солидарность автора и героя в аспекте падения достигают максимальной и даже запредельной степени. Это творчество на краю бездны, когда рушатся барьеры между вымыслом и действительностью, когда тайные силы хаоса получают свободу и магическим образом претворяют фантазии в реальность». Л. Сараскина, Достоевский в созвучиях и притяжениях (от Пушкина до Солженицына), Москва: Русский путь 2006, с. 188. 
и рулеткой. Третью часть произведения составляют последние часы Достоевского и его смерть. В течение всего повествования в форме разных ассоциаций приведены и другие эпизоды его жизни, например, период его службы и эпизоды начала его литературной карьеры. В итоге получается не столько хронологически построенная цельная биография Достоевского, сколько реконструируется его нравственно-психологический облик.

В реконструкции жизни и нравственно-психологического облика писателя участвуют источники разного статуса. Главным из них является Дневник А. Г. Достоевской, который она вела во время поездки с мужем за границу в 1867 году. События и переживания записаны ею стенографическими знаками, которые были расшифрованы тридцать лет спустя после смерти Достоевского. Первое издание этого Дневника ${ }^{8}$ возьмет с собой автор-повествователь романа Цыпкина, чтобы читать его в поезде по пути из Москвы в Петербург. Текст Дневника не только читается повествователем, но и становится основой для его же перефразировки-повествования, благодаря чему создается особая форма пастиша (pastiche). Пастиш - это часто употребляемый прием в постмодернизме, когда с помощью перефразировки и/или стилизации источника, который вовсе не скрывается, а наоборот, становится одним из пластов нового текста, увеличивается количество точек зрения и рождается ирония как основной принцип постмодернистской эстетики.

В романе Цыпкина, благодаря плавному и синтаксически до крайности расширенному дискурсу, простодушные, порой наивные и часто короткие, «деловые» записки А. Г. Достоевской приобретают ореол легкого пафоса, который в то же время проникнут иронией по отношению к субъекту этих же самых записей и к изображенным им событиям и переживаниям. Например, эпизод первой размолвки между супругами описан Анной Григорьевной следующим образом:

Дорогой Федя заметил мне, что я по-зимнему одета (бел. пуховая шляпа), и что у меня дурные перчатки. Я очень обиделась и ответила, что если он думает, что я дурно одета, то нам лучше не ходить вместе, сказав это, я повернулась и быстро пошла в противоположную сторону. Федя несколько раз окликнул меня, хотел за мною бежать, но одумался и пошел прежнею дорогою. Я была чрезвычайно обижена, мне показалось замечание Ф. М. ужасно неделикатным. Я почти бегом прошла несколько улиц и очутилась у Brandenburger Thor, которые выстроены по образцу Пропилеев. Дождик все еще шел, немцы с удивлением смотрели на меня, девушку, которая, не обращая ни малейшего внимания, без зонтика шла по дождю9

${ }^{8}$ Первые две тетради Дневника впервые были изданы в 1923 году. Историю его расшифровок и изданий см.: С. В. Житомирская, Дневник А. Г. Достоевской как историко-литературный источник, [в:] А. Г. Достоевская, Дневник 1867 года, Москва: Наука 1993, [электронный ресурс] http://dostoevskiy-lit.ru/dostoevskiy/dnevnik/dostoevskaya-1867/ prilozhenie-zhitomirskaya-dnevnik-dostoevskoj-kak-istorikoliteraturnyj-istochnik.htm [15.06.2017].

${ }^{9}$ А. Г. Достоевская, Дневник 1867 года, Москва: Наука 1993, [электронный ресурс] http://www.fedordostoevsky.ru/memories/relatives/001 [10.05.2017]. 


\section{Этот же эпизод в повествовании Цыпкина передается так:}

Анна Григорьевна догнала его и, продев свою руку в потертой перчатке под его локоть, виновато взглянула ему в глаза - если бы не она, он показал бы этому лакею, он поставил бы их всех на место! - он медленно перевел взгляд с ее лица на руку ее, лежавшую у него на плече, - «По-моему, в таких перчатках не пристало ходить аккуратной женщине», - медленно отчеканил он и снова перевел свой взгляд на ее лицо - губы ее задрожали, а веки как-то странно вспухли, - она еще шла рядом с ним, но только по инерции и еще потому, что ей казалось, что это относится не к ней, - он не мог сказать такого ей - оставив его, она быстрым шагом, почти бегом свернула в какую-то боковую аллею тоже обсаженную каштанами, на секунду оглянувшись, она увидела сквозь листву и слезы его фигуру, по-прежнему шагавшую по аллее, - на нем был темно-серый, почти черный костюм, купленный в Берлине, - ему даже в голову не пришло тогда сказать ей, чтобы она купила себе новые перчатки, хотя эти уже разъезжались по швам и она еще в дороге, при нем, два раза зашивала их, - теперь он же ее еще и попрекал, хотя деньги на их путешествие были получены от заклада вещей ее матери, - она шла по улице, почти бежала, держась ближе к домам, опустив вуаль, чтобы не было видно ее вспухшего от слез лица... (12-13) ${ }^{10}$.

Такое же полупатетическое-полуироническое отношение характеризует повествовательную манеру Цыпкина и к другим первоисточникам событий избранного периода: к Воспоминаниям А. Г. Достоевской, к ее переписке с мужем, к записям А. Сусловой. Это последнее демонстрирует хорошо известный эпизод поездки Достоевского с А. Сусловой в Италию в качестве ее «брата». В дневнике Сусловой типичная для их отношений во время поездки сцена описана следующим образом:

Дорогой он [Достоевский] сказал мне, что имеет надежду, хотя прежде утверждал, что нет. На это я ничего не сказала, но знала, что этого не будет. [...] Часов в 10 мы пили чай. Кончив его, я, так как в этот день устала, легла на постель и попросила Ф. М. сесть ко мне ближе. [...] - Ты не знаешь, что сейчас со мной было! - сказал он с странным выражением. - Что такое? - Я посмотрела на его лицо, оно было очень взволновано. - Я сейчас хотел поцеловать твою ногу. - Ах, зачем это? - сказала я в сильном смущении, почти испуге и подобрав ноги. - Так мне захотелось, и я решил, что поцелую ${ }^{11}$.

\section{В романе Цыпкина источник перефразируется так:}

[...] они жили в отелях в соседних комнатах, ехали рядом в поезде, занимали одну каюту на пароходе, но они дали друг другу клятву, что будут только друзьями, - вернее, он сам предложил это, иначе она бы не согласилась ехать с ним, предложил, заранее понимая абсурдность этого и смутно, в глубине души, надеясь и веря во что-то иное [...] однажды, накинув на себя халат, он присел к ней - она приподнялась, вся купаясь в своих волосах, и стала отталкивать его, а он припал к одеялу, покрывавшему ее колени, и стал целовать одеяло... (25).

10 Здесь и далее роман цитируется по следующему изданию, с указанием в скобках страниц: Л. Цыпкин, Лето в Бадене, Москва: Новое литературное обозрение 2003.

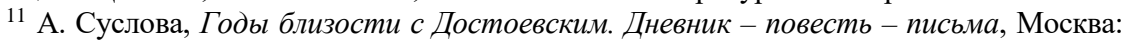
РУССЛИТ 1991, с. 58. 
В реконструкции нравственно-психологического облика Достоевского имеют совсем другой статус и играют другую роль герои его произведений. Этот аспект воспроизведения образа писателя однозначно входит в круг компетенций автора-повествователя, поскольку ни Анна Григорьевна, ни А. Суслова, даже сам Достоевский не могли знать во время баденского лета о будущих романах и их героях. Автор-повествователь, прекрасно знающий все творчество Достоевского, как будто ассоциативно, но на самом деле вполне осознанно, выделяет определенных героев из произведений писателя, проводя параллель по некоторым признакам с психологией их автора. Самый эксплицитный пример - это образы Ставрогина и Федора Карамазова. Ставрогин определяется повествователем как «главная антитеза самому себе [Достоевскому - Т. С.] - сверхчеловек» (20), а в связи с образом Ф. Карамазова подчеркивается факт совпадения имен: «было что-то сладко-уничижительное в том, что Достоевский назвал его своим именем - Федор...» (47). Менее эксплицитно преломляются в личности Достоевского-героя образы других его героев - подпольного человека (записки которого цитируются в эпиграфе к роману), Исая Фомича из романа Записки из мертвого дома, и, конечно, Алексея, игрока из одноименного романа.

На основе выбранных персонажей и их выделенных признаков, психологической доминантой образа Достоевского-героя представляется чувство униженности и постоянные попытки преодолеть это чувство. В первой части романа, охватывающей дрезденскую и баденскую жизнь Достоевских, источником чувства униженности писателя представлено его избиение на каторге. Внутреннее переживание Достоевского-героя при воспоминании сцены своего наказания розгами и, как будто наблюдающих за этой сценой женщин, становится лейтмотивом первой части произведения:

[...] желтые глаза плац-майора с хищно расширившимися зрачками, поспешность, с которой он расстегивал свою арестантскую одежду, чтобы лечь на отполированный сотнями тел низкий дубовый стол, стоявший посредине кордегардии, стоны, которые он не смог сдержать, когда на его тело обрушились удары розог, [...] судорожные корчи, которые начались у него после экзекуции, насмешливые или сострадательные взгляды присутствующих при этом, [...] - все они [женщины - Т. С.] были свидетелями его унижения, и он ненавидел их за это... (14).

Третий аспект в реконструкции нравственно-психологического облика Достоевского представляют собой факты из истории литературы, в первую очередь, сложные и противоречивые отношения писателя в начале его литературной карьеры с В. Белинским, его окружением, а также с И. Тургеневым во время их пребывания в Бадене. Именно эти отношения выступают как источник чувства униженности во второй части романа Цыпкина: 
[...] он продолжал сидеть, то бледнея, то покрываясь краской, а вокруг все смеялись - над ним! над его дружбой! - и Тургенев, его кумир, небрежно облокотившись на спинку кресла, приставив к глазам холодно поблескивающий лорнет, тоже смеялся с остальными... (37).

Кроме перечисленных источников и аспектов образа Достоевского, в романе Цыпкина присутствует еще один аспект - личный интерес автора-повествователя к жизни великого русского писателя: «Почему меня так странно привлекала и манила жизнь этого человека, презиравшего меня и мне подобных?» (92). В связи с его происхождением, семьей и кругом знакомых, главный вопрос автора-повествователя направлен на антисемитизм Достоевского. Кроме Дневника Анны Григорьевны авторповествователь читает еще одну книгу. Приехав в Ленинград-Петербург, в квартире приятельницы, лучшей подруги его матери, он возьмет с полки наугад старый том собраний сочинений Достоевского и начнет читать отрывок из Дневника писателя, а именно статью Еврейский вопрос. Чувства, вызванные текстом Достоевского, сфокусированы в конечном счете на одном вопросе ${ }^{12}$ :

[...] мне показалось до неправдоподобия странным, что человек, столь чувствительный в своих романах к страданиям людей, этот ревностный защитник униженных и оскорбленных, горячо и даже почти исступленно проповедующий право на существование каждой земной твари и поющий восторженный гимн каждому листочку и каждой травинке, - что человек этот не нашел ни одного слова в защиту или в оправдание людей, гонимых в течение нескольких тысяч лет, - неужели он был столь слеп? или, может быть, ослеплен ненавистью? (75)

Прямого ответа на этот вопрос на уровне сюжета нет. Ключ к его решению, на наш взгляд, скрывается в принципе оформления текста как целого, в орнаментальности повествования.

\section{Орнаментализм}

Как мы видим, образ Достоевского в романе Цыпкина, его жизнь и нравственно-психологический облик строятся на основе разных источников, каждый из которых имеет особый статус, примыкает к другому субъекту, жанру и временному пласту. А связаны они с помощью ассоциативного мышления автора-повествователя. Эта сугубо постмодернистская конструкция дополняется принципом орнаментальности, характерным для эстетики модернизма, прежде всего для прозы символистов. На разнородный материал, образующий не очень прочно связанный, фрагментарный сюжет с помощью ассоциаций, надстраивается система

12 Еврейский вопрос в творчестве Достоевского корректно и многопланово рассматривается в работе П. Торопа, Достоевский: логика еврейского вопроса, [в:] он же, Достоевский: история и идеология, Tartu: Tartu University Press 1997, с. 23-56. 
повторяющихся мотивов, которые формируют орнамент, носящий дополнительную смысловую нагрузку по отношению к сюжету ${ }^{13}$.

Орнамент в романе Цыпкина состоит из разных по своей функции повторяющихся мотивов. Самые простые из них - постоянные эпитеты персонажей, взятые прямо из вышеупомянутых источников: «тяжелый взгляд исподлобья〉 Анны Григорьевны, короткие ноги Достоевского, открытая рубашка его пасынка или «львиная голова» Тургенева. На уровне настоящего времени повествования постоянные атрибуты прикреплены к предметам: например, грохот поезда, меняющийся свет за окнами вагона, и вариант этого же мотива - колеблющаяся лампочка в квартире Гили и свет в окнах дома на противоположной стороне улицы.

Наряду с постоянными атрибутами, повторяются некоторые поступки персонажей, воспроизводящие «реальный» мир их жизни в Бадене. Таковы, например, повторяющиеся припадки Достоевского, то, что он стоит на коленах перед женой, покупает ей сладости или же частые прогулки и обеды супругов в Бадене и его окрестностях.

Кроме мотивов, связанных с референциальным миром, к образам Достоевского и Анны Григорьевны прикреплены мотивы-метафоры, образная сторона которых, как правило, связана с «водной стихией». Отношение Анны Григорьевны к своему браку метафорически выражается с помощью повторяющегося мотива «мачты», за которую она ухватилась, и, которая иногда как бы выскальзывает из ее рук в неприятных ситуациях, как, например, при встрече с родней Достоевского:

[...] в квартире у его сестры она ловила на себе неприязненные взгляды домочадцев, потому что они мыслили женить Федю на какой-то своей родственнице, [...] - мачта, за которую она теперь уже прочно держалась, настолько прочно, что даже уже забыла, что она держится за нее - мачта эта вдруг начинала выскальзывать из ее рук... (18).

Интимную сторону супружеских отношений Достоевского и его жены выражает повторяющаяся метафора совместного «плавания», во время которого Достоевского иногда уносит «встречное течение»:

[...] вечером, как всегда, он пришел проститься с ней - они опять заплыли очень далеко, так далеко, что берег скрылся из глаз, как будто его и не было, - они

${ }^{13}$ Определив источники и особенности символистской прозы, Лена Силард делит орнаментальную прозу 1920-х годов на два типа: 1/ «чистая орнаментальность», где прагматичная организованность сюжета полностью пропадает, «где обработанные прежней романной прозой статусы и связи отбрасываются, а персонажи с фрагментами их судеб становятся всего лишь «деталями» мотивного орнамента, охватывающего весь текст»; 2/ связи сюжета сохраняются, но семантическое наполнение мотивных уровней «оказывается не менее значительным, чем романные судьбы персонажей, а также их перемещение из одной ситуации в другую». Л. Силард, Орнаментальность / орнаментализм, «Russian Literature» 1986, № XIX, с. 70. Роман Цыпкина по всей очевидности ближе ко второму типу. 
плыли, ритмично дыша, то погружаясь в воду, то легко вталкиваясь из нее, чтобы набрать в легкие воздух, и когда, казалось, плаванию этому не будет конца, и они вот-вот оторвутся от воды и уже не поплывут, а полетят, словно чайки, свободно и легко паря над морем, он вдруг вспомнил ее смеющееся лицо - конечно же, она смеялась над ним, и какое-то встречное течение стало сбивать его в сторону... (31).

Это самое «встречное течение» вызывает повторяющийся образ «багрового лица с рысьими глазами», принадлежавший плац-майору Кривцову, и, который, в свою очередь, является метафорой главного источника чувства униженности Достоевского.

Мотивы, взятые из произведений Достоевского, как правило, выполняют связывающую функцию между разными мирами и временными пластами произведения. Например, повторяющийся жест «хватание за одежду» служит исходной точкой для выстраивания цепи орнаментов, в которой ассоциативно связаны настоящее и прошлое автораповествователя, разные периоды жизни Достоевского, а также определенные моменты из его романа Бесы. Прибывающий в город Калинин ${ }^{14}$ поезд автора-повествователя вызывает ассоциации с прошлым Достоевского, возвратившегося из Сибири, когда он именно на этой станции бросался «из стороны в сторону, то вправо, то влево, к подъезжавшим к Твери из Москвы или Петербурга» (20). Жест Достоевского, который бегает за высокопоставленными лицами и хватает их за одежду в надежде получить разрешение поселиться в Петербурге, напоминает повествователю Петра Верховенского, «семенившего» за Ставрогиным. От образа Верховенского ассоциация ведет к третьему звену в орнаментальной цепи, к прошлому автора-повествователя, к образу его неудачливого одноклассника-летчика. Отсюда повествование возвращается к образу Ставрогина, потом опять к суетной беготне Достоевского. Свет фонарей за окнами поезда на станции в Калинине напоминает сцену пожара в романе Бесы и образ Лямшина после убийства Шатова. Отсюда переход к более близкому ко времени повествования прошлому автора-повествователя, который в Москве искал место убийства - знаменитый пруд и грот на его берегу. Отсюда возникает ассоциативная связь с братом Анны Григорьевны, который жил недалеко от этого грота. И, как последнее звено в ассоциативной цепи орнамента, отправляющийся со станции в Калинине поезд вдруг перевоплощается в поезд Достоевских, ехавших из Дрездена в Баден.

Похожую функцию выполняет мотив Сикстинской Мадонны, появляющийся не только в одном эпизоде, но охватывающий весь сюжет с его главными временными пластами. Картина с изображением Мадонны появляется в романе Цыпкина в двух ипостасях: как картина-экспонат

14 Калинин - это название города Тверь с 1931 до 1990. Использование этих двух названий города в данном эпизоде произведения Цыпкина также указывает на переплетение разных временных пластов: настоящего повествования и времени жизни Достоевского. 
в музеях и как фото - сделанная с этой же картины репродукция. Общеизвестная сцена встречи Достоевского с оригинальной картиной в Дрезденской галерее передается в форме пастиша, на основе текста Дневника Анны Григорьевны. Параллельно этой сцене следует описание посещения автором-нарратором выставки этой же картины в Москве, в Пушкинском музее, где «выстроилась огромная очередь, пускали порциями, и вот где-то между этажами висела Сикстинская Мадонна...» (11).

Репродукция Сикстинской Мадонны в прошлом висит над диваном Достоевского, когда он умирает в своей петербургской квартире, впоследствии дом-музей, который посещает в конце сюжета автор-повествователь. Подобная репродукция Мадонны стоит на книжной полке тети автора-повествователя, с которой он взял Дневник Достоевской.

Эти два примера - мотивы хватания за одежду и картины Сикстинской Мадонны - прекрасно демонстрируют, как выстраивается с помощью повторяющихся мотивов эквивалентность разных референциальных миров и временных пластов произведения. Согласно концепции В. Шмида, повторяемость и эквивалентность - основные признаки орнаментальной прозы, роднившие ее с мифическим мышлением:

Орнаментализм естественным образом тяготеет к созданию такого мира, в котором господствует архаический циклично-парадигматический порядок. [...] Благодаря своей поэтичности, орнаментальная проза предстает как структурный образ мифа ${ }^{15}$.

Другим отличительным признаком, сближающим орнаментальную прозу с мифическим мышлением, В. Шмид считает тенденцию к иконичности, к стиранию четких границ между повествовательным текстом и рассказываемой историей. В романе Цыпкина, кроме указанных повторов и эквивалентностей, центральную роль играет комплекс мотивов, с помощью которых максимально сближаются сюжетный уровень (биография и нравственно-психологический облик Достоевского) и текстовой уровень произведения со своими орнаментами. Вдобавок, перекодируется и мотивная структура одного из романов Достоевского, а именно романа Игрок.

В центре этого комплекса стоит мотив «вершина», эквивалентами которого служат мотивы «стул», «гора», «треугольник», «угол», «хрустальный дворец», а оппозициями выступают «кратер вулкана», «отрезанный угол», «подножье горы». Они представляют собой бинарную оппозицию «верх-низ», между которыми происходит постоянное метафорическое движение Достоевского-героя: «полетом к открывшейся ему вершине» и спуском «с горы стремглав вниз» (45).

${ }^{15}$ В. Шмид, Проза как поэзия. Пушкин, Достоевский, авангард, с. 116, 119, [электронный ресурс] http://www.rulit.me/books/proza-kak-poeziya-pushkin-dostoevskij-chehovavangard-read-317110-1.html [12.07.2017]. 
Нахождение Достоевского-героя на вершине, как правило, сопровождается мотивом «хохочущей толпы» внизу. Из этого следует, что этот комплекс мотивов находится в теснейшей связи с психологической доминантой образа Достоевского, с чувством униженности и постоянными попытками преодолеть это чувство. Метафорическое движение вверх становится доминантой образа Достоевского на уровне текста, в орнаментах повествования. В этом движении, когда оно появляется в самом разноаспектном виде, соединены все важные моменты жизни, психологии и эстетики писателя: жена Анна Григорьевна, музыка, картина с образом Христа и хрустальный дворец.

[...] играли Эгмонта, и было что-то в этой музыке созвучное громоздящимся вдали горам с нависшими над ними фиолетовыми тучами, подсвечиваемыми отблесками зарниц, - оба они взбирались по круче, она - легко и быстро, следуя прихотливым изгибам тропинки, вьющейся среди кустарника, скал и развалин рыцарских замков, он - по отвесному, почти неприступному склону... [...] он поднимался все выше и выше, преодолевая страшную крутизну, к самой вершине горы, где в фиолетовой туче, прорезаемой вспышками молний, был скрыт хрустальный дворец - это мечта человечества и его собственная мечта, взлелеянная им и глубоко затаенная, так что он даже нарочно обсмеивал эту мечту, но этот горный обвал, заглушающий причитания и хохот беснующейся толпы, и удары грома, обрушивающиеся из фиолетовой тучи, вселяли в него веру в осуществимость этой мечты, в видение картины неизвестного художника ясно показывало ему путь, которым следовало идти, и он уже был на этом пути, взбираясь по отвесной круче... (50-51).

Движение вверх Достоевского-героя завершается в момент его смерти:

[...] ему же казалось, что он взбирается сейчас на самую высокую гору в мире, - она была намного выше тех, на которые он когда-либо всходил или пытался взойти, и ему казалось, что шел он удивительно легко по какой-то прямой, светлой, хрустальной дороге, $[\ldots]$ на самой вершине этой горы сияло яркое солнце, отражаясь в хрустале, по которому он скользил, и, когда он достиг вершины и солнце на миг ослепило его, он увидел, как низки и ничтожны были те горы, на которые он карабкался ранее, - все они были просто жалкими холмиками, и с вершины этой гигантской горы ему открылась не только вся земля с суетой ее обитателей, но вся вселенная с яркими огромными звездами, и на мгновение ему открылись страшные тайны этих отдаленных планет, но солнце в ту же минуту погасло, и он погрузился в страшный, бездонный мрак... (91).

Движению между членами бинарной оппозиции «верх-низ» противостоит другой тип метафорического движения, связанный с игрой: «курсирование» Достоевского-героя между вокзалом (казино) и домом, а также «карусель», захватывающая всех игроков, включая Достоевского у рулетки, где «все кружилось вокруг него в каком-то бешеном вихре» (44).

Двойная структура движения Достоевского-героя в романе Цыпкина (кругообразное и устремленное вверх движение) воспроизводит и перекодирует мотивную структуру самого автобиографического романа Достоевского-писателя Игрок, запечатлевшего как раз «рулеточный» период 
его жизни. В Игроке преобладает именно движение по кругу, и с помощью мотива «круг» обеспечивается эквивалентность разных уровней произведения ${ }^{16}$. Преодоление беспрерывного кругообразного движения происходит только с помощью записок, автор которых, домашний учитель Алексей, постепенно отдаляется от тех событий, которые на сюжетном уровне он не в состоянии преодолеть.

Мотив «горы» в романе Игрок занимает также важное место, прежде всего в своей метафорической функции. На гору Шлангенберг в романе Достоевского никто не поднимается, зато Алексей выражает готовность броситься вниз с ее вершины - что является метафорическим выражением одержимости героя игрой, как рулеточной, так и любовной. Кроме этого, гора и связанный с ней комплекс мотивов активизируют смысловой потенциал маленькой трагедии Пушкина Cкуnой pbцарь и воспроизведенную в ней мифологему об искушении властью17.

В романе Цыпкина, наоборот, падению с горы вниз и круговороту рулеточной игры противопоставлено стремление на вершину горы, которое приобретает абсолютно позитивный смысл. Таким образом, с помощью активизации и перекодирования главных мотивов романа Игрок в орнаментальной системе романа Цыпкина расширяется смысловой потенциал, который задан на сюжетном уровне при воспроизведении нравственно-психологического облика Достоевского с помощью других его произведений и героев (см. П. Верховенский, Ф. Карамазов, подпольный человек). То есть, акцент с состояния и чувства униженности, которые являются доминантой образа Достоевского на сюжетном уровне, переносится на преодоление этого чувства и состояния на уровне орнаментального пласта текста. Это вполне совпадает с позицией В. Шмида, который утверждает, что «ассоциативное умножение нарративных смыслов и нарративное использование словесного искусства предоставляют сложные возможности изображения человека и его внутреннего мира» ${ }^{18}$.

Подводя итог сказанному, можно сделать вывод, что в романе Цыпкина Лето в Бадене, благодаря принципу орнаментальности, создается структура, близкая к мифической модели мира ${ }^{19}$. Само это произведение

${ }^{16}$ См. об этом: Т. Сабо, Теория хаоса $и$ «Игрок» Достоевского, [в:] Поэтика Достоевского. Статьи и заметки, Riga: LU Akadēmiskais apgāds 2007, с. 36-44.

${ }^{17}$ См. об этом: Т. Сабо, Тема искушения в «Игроке» Ф. М. Достоевского и в «Скупом рыщаре» А. С. Пушкина, «SLAVICA» 2002, № 31, с. 123-133. Поскольку в связи с образом Достоевского неизбежим вопрос о его отношении к Пушкину, в тексте Цыпкина он тоже затронут и суммирован в антитезе: «[...] прозаик Достоевский был, может быть, самым страстным поэтом и романтиком своего времени, в то время как Пушкинпоэт был, может быть, самым трезвым реалистом...» (61).

${ }^{18}$ В. Шмид, Проза как поэзия..., с. 304.

19 Это подтверждается и присутствием элементов подсознательного, которое, согласно концепции В. Шмида, приравняется к мифическому восприятию мира в орнаментальной прозе. Поэтому нельзя согласиться с критикой, которая утверждает, что роман Цыпкина оперирует вульгарным фрейдизмом (см. цит. статью М. Эдельштейна). В романе Лето в Бадене речь идет скорее о присутствии подсознательного как параллели мифологического мышления. 
представляет собой новую, постмодернистскую версию мифа о Достоевском-игроке, с использованием при этом важнейших источников этого мифа: Дневник и Воспоминания Анны Григорьевны, ее переписку с мужем, записки А. Сусловой, труды достоевсковедов, материалы Музея Достоевского, и, конечно, произведения и записные книжки самого писателя. В центр воспроизведенного нравственно-психологического облика Достоевского ставится чувство униженности и постоянные попытки преодолеть его. Это стремление с помощью орнаментального пласта произведения предстает как нечто мифическое, т. е. универсальное в человеческой жизни. Благодаря эквивалентности разных референциальных миров и временных пластов романа Лето в Бадене, к этой общечеловеческой судьбе причастны все, не только Достоевский-герой, но и персонажи его произведений, включая «презираемых» им евреев, а также автор-повествователь и его современники, жертвы ленинградской блокады и все угнетенные советской властью.

Таким образом, ответ на заданный на уровне сюжета личный вопрос автора-повествователя заключен в орнаментальности его прозы, в которой постмодернистский миф о герое XIX века строится с учетом опыта символистов-модернистов.

\section{References}

Chuprinin, Yunna. „170 stranic pro ljubov”. Itogi, № 19, (2003). http://www.itogi.ru/archive/2003/19/82612.html

Cypkin, Leonid. Leto v Badene. Moskva: Novoye literaturnoye obozrenie, 2003. http://www.imwerden.info/belousenko/books/russian/tsypkin_baden.htm

Edelstein, Mihail. „Leonid Cypkin. Leto v Badene”. Znamya, № 6, (2004). http://magazines.russ.ru/znamia/2004/6/ed21.html

Epstein, Mikhail. Postmodernizm i kommunizm. In: Postmodernizm v russkoy literature. Moskva: Vysshaya shkola, 2005: 67-93.

Kyakshto, Nataliya. H. Russkiy postmodernizm. In: Russkaya literatura XX veka. Shkoly, napravleniya, metody tvorcheskoy raboty, ed Svetlana I. Timina. Moskva: Logos, 2002: 305-326.

Lemhin, Mihail. „Doktor Cypkin i doktor Gindenburg”. Novy mir, № 6, (2004). http://magazines.russ.ru/novyi_mi/2004/7/lem11.html

Levinton, Aleksandr. Roman dlinoyu v neskolko abzacev. http://berkovich-zametki.com>Nomer37/Levintov1.htm

Saraskina, Ludmila. Dostoevsky v sozvuchiyah i prityazaniyah (ot Pushkina do Solzhenicyna). Moskva: Russkiy put, 2006.

Schmid, Volf. Proza kak poeziya. Pushkin, Dostoevsky, Chekhov, avangard. http://www.rulit.me/author/shmidvolf/proza-kak-poeziya-pushkin dostoevskij-chehovavangard-download-free-317110.html

Suslova, Apollinariya. Gody blizosti s Dostoevskim. Dnevnik - povest - pisma. Moskva: Russlit, 1991.

Szabó, Tünde. „Tema iskusheniya v 'Igroke' F. M. Dostoevskogo i v 'Skupom rytsare' A. S. Pushkina”. SLAVICA, № 31, (2002): 123-133. 
Szabó, Tünde. Teoriya khaosa i „Igrok” Dostoevskogo. In: Poetika Dostoevskogo. Stati i zametki. Riga: LU Akadēmiskais apgāds, 2007: 36-44.

Szilárd, Lena. „Ornamentalnost / ornamentalism”. Russian literature, № XIX, (1986): 65-78.

Torop, Peeter. Dostoevsky: logika yevreyskogo voprosa. In: Dostoevsky: istoriya i ideologiya. Tartu: Tartu University Press, 1997: 23-56.

Turovskaya Maya. „Leto v Badene”. Zarubezhnye zapiski, № 2, (2005). http://magazines.russ.ru/zz/2005/2/tu13.html

Zhitomirskaya, Sarra. V. Dnevnik A. G. Dostoevskoy kak istoriko-literaturny istochnik. In: Dostoevskaya, Anna. G. Dnevnik 1867 goda. Moskva: Nauka, 1993. http://dostoevskiylit. ru/dostoevskiy/dnevnik/dostoevskaya1867/prilozhenie-zhitomirskaya-dnevnik-dostoevskoj-kak-istoriko-literaturnyj-istochnik.htm 